\title{
BILINGUISMO E INCLUSÃO: UMA REFLEXÃO SOBRE OS ALUNOS SURDOS NA REDE REGULAR DE ENSINO
}

DOI: $10.48075 /$ ri.v24i1.27162

Melissa Probst ${ }^{1}$

RESUMO: O presente artigo, sobre o bilinguismo e a educação de surdos, na perspectiva da inclusão dos surdos na rede regular de ensino, tem como pano de fundo estudos e discussões realizados ao longo de um curso de especialização em Letras e Libras. Caracterizado como bibliográficodocumental, o estudo objetivou refletir sobre as contribuições do bilinguismo para a inclusão escolar de crianças surdas; apresentar aspectos alguns legais da inclusão do surdo na educação escolar; discutir sobre elementos da cultura e identidade surda, e, por fim, refletir sobre o bilinguismo como ferramenta/estratégia positiva para a inclusão escolar. $O$ estudo encontra ancoragem nos documentos legais (leis, decretos etc.) e nas proposições teóricas apresentadas por Quadros (2003; 2004; 2008, 2000) e Skliar (2000; 2003a; 2003b), entre outros. Os resultados apontam que trabalhar numa perspectiva inclusiva requer esforço conjunto de todos os atores educacionais, uma vez que é necessário pensar de forma coletiva numa perspectiva de educação bilingue, na qual o aprendizado de outra língua não seja benéfico apenas ao surdo. Aos ouvintes, aprender Libras também possibilita o fortalecimento das estruturas linguísticas, ou seja, favorece o desenvolvimento cognitivo e amplia os horizontes dos estudantes, incentivando o pensamento criativo e permitindo um acesso maior à comunicação.

Palavras-chave: Educação, Bilinguismo, Inclusão.

\section{BILINGUALISM AND INCLUSION: A REFLECTION ON DEAF STUDENTS IN THE REGULAR EDUCATION}

ABSTRACT: This article, on bilingualism and deaf education, from the perspective of including deaf people in the regular school system, has as its background studies and discussions carried out during a specialization course in Letters and Libras. Characterized as bibliographic documentary, the study aimed to reflect on the contributions of bilingualism to the school inclusion of deaf children; present some legal aspects of the inclusion of the deaf in school education; discuss about elements of deaf

\footnotetext{
${ }^{1}$ Doutora em Educação pela Universidade Tuiuti do Paraná. Mestra em Educação pela Universidade Regional de Blumenau. Especialista em Orientação, supervisão e gestão escolar pelo Instituto Catarinense de Pósgraduação; Especialista em Educação a distância: gestão e tutoria pelo Centro Universitário Leonardo da Vinci; Especialista em Letras e Libras pelo Centro Universitário Faveni. Licenciada em Pedagogia pela Universidade Regional de Blumenau; Licenciada em História pelo Centro Universitário Leonado da Vinci; Bacharela em Filosofia pelo Centro Universitário Uninter. Coordenadora Pedagógica na rede municipal de ensino de Blumenau-SC. E-mail: mel.probst@gmail.com.
} 
culture and identity, and, finally, reflect on bilingualism as a positive tool / strategy for school inclusion. The study is anchored in legal documents (laws, decrees, etc.) and in theoretical propositions presented by Quadros (2003; 2004; 2008, 2000) and Skliar (2000; 2003a; 2003b), among others. The results show that working in an inclusive perspective requires a joint effort from all educational actors, since it is necessary to think collectively in a perspective of bilingual education, in which learning another language is not beneficial to the deaf. For listeners, learning Libras also enables the strengthening of linguistic structures, that is, it favors cognitive development and broadens students' horizons, encouraging creative thinking and allowing greater access to communication.

Key Words: Education, Bilingualism, Inclusion.

\section{INTRODUÇÃO}

No atual contexto educacional brasileiro, a temática da inclusão vem sendo amplamente discutida, desde o âmbito das políticas públicas até a formação inicial e continuada de professores. Entretanto, no que se concerne à realidade educacional, ainda é perceptível uma grande lacuna entre as proposições teóricas e legais (legislação) e o que é vivenciado pelos estudantes nas escolas. Além disso, embora a inclusão seja amplamente debatida, essa discussão acaba abarcando aspectos generalistas, pouco direcionados, de modo que a educação dos surdos ainda seja um assunto inquietante para grande parcela dos profissionais da educação.

Assim, a partir da urgência de tal discussão, o presente artigo, que tem como objeto de discussão o bilinguismo e a educação de surdos, na perspectiva da inclusão dos surdos na rede regular de ensino, tem como pano de fundo estudos e discussões realizados ao longo de um curso de especialização Letras e Libras. Nesse âmbito, compreende-se a Libras (Língua Brasileira de Sinais) como primeira língua utilizada pelos surdos, entretanto, optou-se por, mas também porque o bilinguismo é importante cotidianamente no encontro entre surdoouvinte, ou surdo-ouvinte bilíngue.

O estudo teve como problema norteador a seguinte questão: Quais as contribuições do bilinguismo para a inclusão escolar de crianças surdas? Para responder tal questão, partiu-se do pressuposto de que a educação bilíngue para surdos deveria, em primeiro lugar, transcender a questão linguística, já que, ser surdo, no atual contexto, abrange também questões socioculturais, políticas e, principalmente identitárias. Além disso, no contexto escolar, o surdo está inserido entre os ouvintes e o bilinguismo pode auxiliar o seu desenvolvimento social-cognitivo, na medida em que, sem renunciar a sua identidade 
cultural, de modo que o estudante possa transitar entre duas diferentes culturas, ampliando seu repertório linguístico.

O presente artigo, caracterizado bibliográfico-documental, encontra ancoragem nas legislações pertinentes à educação e educação inclusiva, e em proposições teóricas apresentadas por Quadros (2003; 2004; 2008, 2000) e Skliar (2000, 2003a; 2003b), entre outros autores discutidos ao longo do curso de especialização Letras e Libras. No que concerne aos objetivos, o estudo buscou, como objetivo geral, refletir sobre as contribuições do bilinguismo para a inclusão escolar de crianças surdas. Enquanto objetivos específicos, pretendeu-se apresentar aspectos alguns legais (leis, decretos etc.) da inclusão do surdo na educação escolar; discutir sobre elementos da cultura e identidade surda, e, por fim, refletir sobre o bilinguismo como ferramenta / estratégia positiva para a inclusão escolar.

\section{ASPECTOS LEGAIS DA INCLUSÃO ESCOLAR DE CRIANÇAS SURDAS}

Muitas das conquistas no contexto da educação especial e da educação inclusiva são originárias de movimentos sociais, das lutas dos grupos sociais minoritários pela conquista e efetivação de direitos. Durante muito tempo as pessoas com deficiência foram alijadas da convivência e participação social, e foram os movimentos sociais que thes deram voz e visibilidade, e Ihes permitiram diversas conquistas, no sentido de serem reconhecidos e respeitados.

No que concerne à educação de surdos, temos hoje, como consequência positiva dos movimentos sociais, políticas públicas que garante o acesso e permanência dos surdos nas instituições escolares, desde a Educação Infantil até o Ensino Superior e até mesmo na pósgraduação. Além disso, entre outras conquistas, temos também a oficialização e reconhecimento legal da Libras como meio de comunicação e expressão das comunidades surdas brasileiras.

No contexto das conquistas legais acerca da educação especial na perspectiva da educação inclusiva, cabe destacar que, independentemente de qual seja a deficiência, todas as pessoas têm o direito à educação garantida pela Declaração Universal dos Direitos Humanos (1948), direito este que foi reafirmado pela Declaração de Salamanca de (1994) e pela Convenção Interamericana para a Eliminação de Todas as Formas de Discriminação contra a Pessoa Portadora de Deficiência (1999). No caso brasileiro, o atendimento à alunos com deficiência se organizou, inicialmente, como atendimento educacional especializado em 
substituição à educação em escolas regulares. Dessa forma, esse atendimento inicial às crianças com deficiência é marcado pela criação de instituições especializadas, escolas especiais e classes especiais (BRASIL, 2008).

O atendimento educacional às pessoas com deficiência esteve, no contexto brasileiro, historicamente fundamentado pela Lei no 4.024 (BRASIL, 1961), que apontava o direito dos "excepcionais" à educação no sistema geral de ensino. Após o golpe militar de 1964, a legislação sobre as diretrizes e bases da educação nacional foi revista, e podemos notar um retrocesso na Lei no 5.692 (BRASIL, 1971), a partir da qual é definido o "tratamento especial" aos alunos com deficiências físicas, mentais, bem como os que se encontram em atraso considerável quanto à idade regular de matrícula e os superdotados. Tal lei reforça o encaminhamento desses alunos para instituições especializadas ou escolas especiais, contribuindo para um panorama de exclusão.

o exemplo dos surdos é, neste sentido, particularmente claro: para a maioria dos ouvintes, a surdez representa uma perda da comunicação, um protótipo de autoexclusão, de solidão, de silêncio, obscuridade e isolamento. Em nome dessa representação se praticaram e se praticam as mais inconcebíveis formas de controle de seus corpos, mentes e linguagem. Entre os controles mais significativos, pode mencionar-se: a violenta obsessão para fazê-los falar [...] (SKLIAR, 2003b, p. 21).

No ano de 1973, sob a perspectiva da integração social, ocorreu a criação do Centro Nacional de Educação Especial - CENESP, que deveria atuar

[...] de forma a proporcionar oportunidades de educação, propondo e implementando estratégias decorrentes dos princípios doutrinários e políticos, que orientam a Educação Especial no período pré-escolar, nos ensinos de 1ㅇ e 2ㅇ graus, superior e supletivo, para os deficientes da visão, audição, mentais, físicos, educandos com problemas de conduta para os que possuam deficiências múltiplas e os superdotados, visando sua participação progressiva na comunidade (BRASIL, $1973, \mathrm{~s} / \mathrm{p}$.$) .$

Desde então, podemos destacar a Constituição Federal (BRASIL, 1988) como grande marco positivo para a inclusão das pessoas com deficiência, impulsionando a defesa de um direito inalienável: o de educação para todos. De acordo com Pietzak e Probst (2017, p. 119),

podemos destacar a Constituição Federal (BRASIL, 1988), que no art. 206, inciso I determina como um dos princípios para o ensino a igualdade de condições de acesso e permanência na escola, ou seja, todos os alunos têm o direito de frequentar a escolar, independentemente da deficiência apresentada. Já no art. 208, inciso III, é garantido aos alunos com necessidades especiais o atendimento educacional especializado de forma complementar, não substitutiva. Neste mesmo artigo, no inciso $\mathrm{V}$, a constituição preconiza ainda a garantia a todos os alunos o direito de acesso aos níveis de ensino, pesquisa e criação artística, de acordo com a capacidade de cada um e que o Ensino Fundamental é obrigatório. 
Mais recentemente, foi a Lei 9.394 (BRASIL, 1996) que passou a traçar diretrizes mais específicas para a educação de pessoas com deficiência, sendo mais um marco histórico nas conquistas educacionais dos alunos com deficiência. Conforme destaca Kassar (2011), a partir de então, tanto os discursos acerca da educação inclusiva quanto o conjunto de políticas públicas sociais tomam corpo no país, e aos poucos o termo "inclusão" vai sendo utilizado, no lugar da anterior perspectiva da integração social. Conforme assevera Skliar (2003a), a proposição de que a educação de surdos deve ser incluída no debate geral sobre educação, não deve e não pode nem deve ser interpretada simplesmente como uma proposta implícita de integração escolar. Para além do simples direito à educação (que obviamente se estende aos surdos), esse direito deve ser analisado, avaliado e planejado junto aos surdos, numa perspectiva de educação integral, significativa e equitativa, sem as restrições que perpassam as vias da caridade, assistencialismo ou dos modelos terapêuticos.

Na perspectiva da inclusão é a sociedade em geral (portanto, também as escolas) que se preparam para receber e incluir as pessoas com necessidades especiais, para que estas possam participar de todas as atividades, em conjunto com as pessoas em geral. De acordo com Kassar (2011) foi, mais especificamente, no decorrer do ano 2000 que o Brasil passou a implantar uma política que pode ser denominada de Educação Inclusiva.

\footnotetext{
Pressionado por oferecer atendimento aos alunos que possuem deficiências, desde 2003 o Governo Federal opta pela matrícula dessa população em salas comuns de escolas públicas, acompanhado (ou não) de um atendimento educacional especializado, prioritariamente na forma de salas de recursos multifuncionais (KASSAR, 2011, p. 72).
}

E no contexto das políticas públicas educacionais postas em práticas nos anos 2000 , podemos destacar a Lei 10.436 (BRASIL, 2002), como um divisor de águas na história educacional dos alunos surdos, uma vez que tal legislação reconhece, como meio legal de comunicação e expressão a Libras (art. 1ํ), bem como prevê a inclusão da Libras nos cursos de formação de Educação Especial, de Fonoaudiologia e de Magistério, em seus níveis médio e superior (art. 4ㅇ).

E recentemente, o tema do bilinguismo ganhou grande repercussão com a aprovação da Lei n. 14.191/21 (BRASIL, 2021), considerada a conquista mais significativa no processo de luta da comunidade surda. Tal legislação altera a Lei $n$ o 9.394/96 (BRASIL, 1996), para dispor sobre a modalidade de educação bilíngue de surdos. A partir de então, previsto no capítulo V-A, artigo 60-A, entende-se que a educação bilingue como 
modalidade de educação escolar oferecida em Língua Brasileira de Sinais (Libras), como primeira língua, e em português escrito, como segunda língua, em escolas bilíngues de surdos, classes bilíngues de surdos, escolas comuns ou em polos de educação bilíngue de surdos, para educandos surdos, surdo-cegos, com deficiência auditiva sinalizantes, surdos com altas habilidades ou superdotação ou com outras deficiências associadas, optantes pela modalidade de educação bilíngue de surdos (BRASIL, 2021, online).

A legislação prevê ainda que a oferta da educação bilingue deverá ser iniciada ainda com os bebês, na educação infantil, e se estenderá ao longo da vida. Sobre isso, Souza (et al, 2014) enfatizam que é muito importante que o surdo tenha, desde a educação infantil, a mesma educação que os ouvintes, pois é essencial que a criança surda tenha oportunidades de interagir com a língua de sinais desde a mais tenra idade. Desse modo, além da crescente necessidade de conhecimentos, mesmo que rudimentares da Libras pelos professores, é fundamental que o professor utilize de vários recursos para estabelecer a comunicação e a interação em sala de aula, tornando o ambiente mais agradável e inclusivo para todos os estudantes.

\section{CULTURA E IDENTIDADE SURDAOSSÍVEIS}

Conforme já mencionado, o Brasil reconheceu a Libras por meio da Lei 10.436 (BRASIL, 2002), e o bilinguismo pela Lei n. 14.191/21 (BRASIL, 2021), ambas consideradas vitórias da luta dos surdos pelos seus direitos. O reconhecimento legal da Libras e do bilinguismo são, sem dúvidas, possibilidades de exercício da cidadania e elementos de afirmação da identidade e da cultura surda. Afirmamos, portanto, a existência de identidades surdas, que permitem a constituição da comunidade surda, na qual os elementos conjugam uma cultura que lhes é própria.

Cada vez mais as culturas "nacionais", "oficiais" estão sendo produzidas a partir da perspectiva das minorias. O resultado desse processo não deve ser apenas compreendido [...] não no sentido de uma proliferação de histórias alternativas dos excluídos, mas sim como uma necessidade de revisão radical em torno do conceito de cultura e comunidade humana (SKLIAR; QUADROS, 2000, p. 36).

Por muito tempo essas identidades foram vistas como "estranhas", ou ainda como "desviantes", uma vez que se apoiam em padrões preestabelecidos de semelhança e diferença, conforme aponta Woodward (2012). Isso porque a forma com que a identidade é vivida é sempre mediada pelos significados culturais, e sempre o conceito de cultura vigente (portanto considerado válido) em uma sociedade é produzido por sistemas dominantes de 
representação, o que acaba por gerar preconceito e discriminação de todas as manifestações culturais que sejam diferentes da estabelecida.

É importante ressaltar que a cultura tem como base as relações produzidas no cotidiano de cada grupo, seja nas relações de classe, de gênero, comerciais, religiosas etc. Não há uma só cultura, homogênea, que seja capaz de abarcar todas as manifestações de hábitos, gostos, tradições e regras de todos os indivíduos. A cultura combina os signos simbólicos, imateriais (como crenças, hábitos, regras, valores, entre outros.) símbolos materiais (arquitetura, roupas, utensílios etc.), e vai, assim, produzindo o que Geertz (1978) denominou de "teia de significados".

[...] quando vista como um conjunto de mecanismos simbólicos para controle do comportamento, fontes de informação extrassomáticas, a cultura fornece o vínculo entre o que os homens são intrinsecamente capazes de se tornar e o que eles realmente se tornam, um por um [...] (GEERTZ, 1978, p. 64).

Podemos afirmar então que o homem é resultado do seu meio cultural, e como tal, é herdeiro do conhecimento e das experiências que perpassam o grupo com o qual se identifica, comunidade da qual faz parte. A manutenção desses conhecimentos e experiências não é inata ao homem, mas é resultante do esforço de todo o grupo, sempre na intenção de preservar sua própria identidade como grupo ou comunidade Woodward (2012, p. 19) ressalta que "a cultura molda identidade ao dar sentido à experiência e ao tornar possível optar, entre várias identidades possíveis, por um modo específico de subjetividade $[\ldots]^{\prime \prime}$.

Nesse contexto, os surdos também são produtores de cultura, pois compartilham e conhecem os usos e normas de uma mesma língua, normas e valores. E sobre isso, é possível afirmar:

\footnotetext{
As comunidades surdas, como espaços de partilha linguística e cultural presentes em milhares de cidades do mundo, reúnem surdos e ouvintes - em geral, usuários de línguas de sinais - com interesses, expectativas, histórias, olhares ou costumes comuns. A ideia de comunidade, aqui, apoia-se na presença de vínculos simbólicos que congregam sujeitos - concentrados em um mesmo local ou dispersos territorialmente - com interesses comuns e propostas coletivas. $\mathrm{O}$ termo, corrente nos Estudos Surdos e entre militantes e profissionais ligados à causa Surda, é comumente usado em sua acepção ampla (por vezes, de forma aligeirada e vaga) para delimitar os espaços de existência (e resistência) de uma minoria linguística com marcadores culturais próprios (HEIJI, online, s/p).
}

Sobre isso, Quadros (2004, p. 10) afirma que "a identificação dos surdos se situa culturalmente dentro das experiências visuais. Entende-se cultura surda como a identidade cultural de um grupo de surdos que se define enquanto grupo diferente de outros grupos". 
É, portanto, uma cultura própria do surdo, na qual pensamento e a linguagem são de ordem visual e por isso é muito difícil de ser compreendida pelas pessoas ouvintes, pois as formas de organização, pensamento e linguagem compartilhadas pelos indivíduos surdos transcendem as formas ouvintes.

A partir do exposto, considera-se indiscutível que não há uma só cultura, nem na sociedade, tampouco na escola. Há culturas, no plural, e, educador precisa ter clareza de que uma cultura difere da outra, não apenas pelo enunciado, mas também pelas tramas de poder e pelas narrativas que a constituem, e, principalmente, que a nossa sociedade ainda é atravessada por ideologias que geram o efeito de naturalização da superioridade das culturas ouvintes sobre as surdas.

\begin{abstract}
A representação de surdez está associada ao significado de deficiência, ou seja, incapacidade, incompetência, falta, falha, insuficiência. As representações das pessoas surdas enquanto deficientes, mutilados, inferiores, incapazes, sem linguagem... estão nas falas das pessoas, nos seus comentários, nas suas perguntas, nos seus comportamentos, enfim, nas suas mentes (QUADROS, 2003, p. 92).
\end{abstract}

Consideramos necessário que o educador, ao planejar suas aulas, e ao avaliar suas próprias práticas, se permita refletir sobre as atitudes, condutas e representações sociais sobre o surdo e a surdez na sociedade, na escola e na sua sala de aula. Destarte, no ambiente escolar cabe ao educador repaginar alguns pontos, de forma que a cultura/identidade surda não seja mais marginalizada, ou vista como subalterna ou deficitária, promovendo uma educação que seja inclusiva de fato, e estimulando experiência de bilinguismo, não apenas para os indivíduos surdos, mas para todos os envolvidos no processo educativo.

\title{
A IMPORTÂNCIA DO BILINGUISMO NA EDUCAÇÃO / INCLUSÃO ESCOLAR
}

Conforme já mencionado anteriormente, o indivíduo surdo percebe o mundo de modo diferente dos ouvintes. Nesse contexto, a língua de sinais e as experiências visuais são os modos pelos quais os surdos criam meios de percepção e comunicação com o mundo. Diferentemente das crianças ouvintes, que quando nascem já pertencem à um ambiente linguístico e, portanto, já chegam à escola falando a sua língua materna, as crianças surdas, de modo geral, não participam dessa mesma imersão linguística. A partir de tal situação, surgem diferentes demandas, tanto para a família quando para a escola, para que ocorra a 
oferta de condições para que essa criança consiga estabelecer comunicação, bem como consiga socializar e aprender.

Para a criança surda, o desenvolvimento da socialização, comunicação e aprendizado ocorre por meio da aquisição da Libras. Entretanto, como essa criança está imersa num contexto de ouvintes, seu desenvolvimento passa também pelo aprendizado da Língua Portuguesa (na modalidade escrita). De acordo com o Ministério da Educação (BRASIL, 2006, p. 34), "a capacidade de comunicação linguística apresenta-se como um dos principais responsáveis pelo processo de desenvolvimento da criança surda em toda a sua potencialidade, para que possa desempenhar seu papel social e integrar-se verdadeiramente na sociedade".

A mediação do professor bilingue e conhecedor de sua língua materna á fundamental, nesse processo, posto que, anteriormente à proposição de leitura de um texto com seus alunos, deverá debruçar-se em um planejamento detalhado que considere as pistas imagéticas entrecruzadas na semiose verbal e não-verbal textual, as pistas da autoria, do contexto de produção, da intenção do texto, do gênero em que ele se insere (FERNANDES, 2012, p. 43)

E é justamente por isso que que "os surdos têm direito a uma educação bilíngue, que priorize a língua de sinais como sua língua natural e primeira língua, bem como o aprendizado da língua portuguesa, como segunda língua" (BRASIL, 2006, p. 71). Destaca-se que a educação bilingue consiste na aquisição de duas línguas: Libras e a Língua Portuguesa nas modalidades oral e escrita, enfatizando que a primeira língua será sempre a Libras (L1) e a segunda língua será a Língua Portuguesa (L2).

\footnotetext{
Essa língua primeira só pode fazer parte e dar vida à criança surda, se ela estiver imersa no fluxo de enunciações em Libras. A escola e as associações são, em geral, os espaços em que se espera a imersão da pessoa surda em sua língua primeira. Por esse motivo, são tão importantes as escolas de educação bilíngue para as crianças surdas, pois constituem o lugar privilegiado para que a criança surda tenha um desenvolvimento linguístico (isto quer dizer também cognitivo e afetivo) similar ao das crianças ouvintes (SOUZA; LIPPE, 2012, p. 16).
}

Desse modo, cabe ressaltar que o bilinguismo não é um método educacional, tampouco uma proposta nova, desconhecida aos profissionais da educação, afinal, O bilinguismo começou a ganhar força a partir da década de 1980 e, no Brasil, a partir de 1990. Pode-se considerar o bilinguismo como uma proposta de socialização e inclusão do indivíduo surdo às comunidades ao seu entorno, sejam essas comunidades surdas ou ouvintes.

Quadros (2003) ressalta que essa não é tarefa ou discussão simples, uma vez que tais proposições estão sempre impregnadas de questões políticas, sociais e culturais que não podem ser desconsideradas pela escola e pelos docentes. Isso porque ainda é muito 
presente no contexto educacional atual uma prática em que a Libras é transpassadas de estereótipos, que fazem com que a língua visual-espacial seja vista apenas como um "recurso a mais" (desconsiderando-a em sua completude linguística), ou ainda, como menciona Quadros (2003, p. 96), "utilizada como meio para ensinar a língua portuguesa e não enquanto razão que se justifica por si só: direito da pessoa surda de usar a sua língua, uma língua que traduz a experiência visual". O bilinguismo entende a surdez como diferença linguística e não como uma deficiência a ser normalizada por meio da reabilitação.

Tornar-se letrado numa abordagem bilíngue pressupõe a utilização de língua de sinais para o ensino de todas as disciplinas. [...]. Faz também parte do projeto bilíngue que todo o corpo de funcionários da escola, surdos e ouvintes, e os pais, aprendam e utilizem a língua de sinais (BOTELHO, 2002, p. 112).

Em sendo assim, ao pensar na educação de surdos é sempre importante refletir sobre a postura dos docentes, afinal, a educação bilíngue não é uma questão de condescendência, é um direito garantido na legislação. "Nesse contexto, a língua não pode ser limitada ao caráter instrumental, não pode servir para afirmar a outra língua, no caso, a portuguesa; mas passa a ocupar espaços que se justificam a partir de comunidades linguísticas legítimas" (QUADROS, 2008, p.15).

\section{CONSIDERAÇÕES FINAIS}

Para quem conhece a realidade educacional brasileira, sabe que é inquestionável o fato de que a maioria dos professores, ainda emprega como método de ensino a exposição oral e utiliza como recurso privilegiado o quadro de giz. Nesse contexto, a principal consequência que ocorre em alunos surdos é a dificuldade que eles encontram para se comunicar com o mundo ao seu redor. As demais implicações, quase sempre, são derivadas dessa primeira, afinal, uma das principais funções da linguagem é a de intercâmbio social. Contudo, "constituir sistema simbólico, que nos permite o pensamento generalizante, ordenando e categorizando dados da realidade, conceitualmente, é que a torna base do pensamento" (BRASIL, 2006, p. 73).

$\mathrm{Na}$ escola, muitas vezes, os processos de interação e comunicação entre os alunos surdos e os adultos (docentes) são pauperizados, com conteúdo substancialmente reduzido, devido, principalmente, à falta de domínio de um código de comunicação comum para ambos. Muitas vezes os alunos surdos são contemplados $\mathrm{cm}$ a presença do intérprete de 
Libras, porém, o professor das disciplinas desconhece os meios para se comunicar com estes alunos, provocando lacunas no processo de ensino e aprendizagem.

Conhecer os elementos necessários para que o surdo se desenvolva é essencial. Quando nos referimos ao potencial cognitivo do surdo, nos remetemos, imediatamente, à qualidade das interações que este pode estabelecer com as pessoas que o rodeiam, tanto no ambiente escolar quanto familiar. Desse modo, acredita-se que o trabalho a ser realizado com os alunos surdos deva ser embasado no uso de um código comunicativo comum no campo educacional, a partir de uma perspectiva bilingue, considerado a Libras como L1.

Trabalhar numa perspectiva inclusiva requer esforço conjunto de todos os atores educacionais. Há que se pensar, de forma conjunta na concepção e adaptação do currículo, na flexibilização organizacional das aulas, bem como na distribuição de recursos pedagógicos que possam auxiliar tanto ao professor quanto aos alunos, de modo geral, no processo de aquisição/construção do conhecimento. Mas também é preciso conscientização a respeito da concepção de surdez como uma "diferença", e não como uma deficiência, bem como respeito ao direito linguístico dos surdos como um direito coletivo.

Destarte, numa perspectiva de educação bilingue, o aprendizado de outra língua não é benéfico apenas ao surdo. Mas aos ouvintes, aprender Libras também possibilita o fortalecimento das estruturas linguísticas, ou seja, vai favorecer o desenvolvimento cognitivo e ampliar os horizontes das crianças, incentivando o pensamento criativo e permitindo um acesso maior à comunicação. Hort e Hort (2009, p.45) destacam que “propiciar a inclusão escolar é participar de um processo de mudança, reorganizando a escola, onde estar incluído significa ter o direito de aprender junto, independente das condições físicas, linguísticas, sociais e emocionais [...]”, ou seja, o movimento de inclusão escolar está sem exceção, para todos os alunos. O sistema educacional deve estar adequado para receber todos os alunos, e, cada vez mais, faz-se preciso provocar os educadores (bem como demais profissionais da educação) a buscar meios para atender, com qualidade, os seus alunos, principalmente a partir da formação inicial quanto continuada.

\section{REFERÊNCIAS}

BOTELHO, P. Linguagem e letramento na educação dos surdos: ideologias e práticas pedagógicas. Belo Horizonte: Autêntica, 2002. 
BRASIL. Constituição da República Federativa do Brasil de 1988. Disponível em: <http://www.planalto.gov.br/ccivil_03/Constituicao/Constituicao.htm>. Acesso em 15 dez 2020.

BRASIL. Decreto 6.571, de 17 de setembro de 2008. Dispõe sobre o atendimento educacional especializado, regulamenta o parágrafo único do art. 60 da Lei no 9.394, de 20 de dezembro de 1996, e acrescenta dispositivo ao Decreto n. 6.253, de 13 de novembro de 2007.

BRASIL. Lei no 4.024, de 20 de dezembro de 1961. Fixa as Diretrizes e Bases da Educação Nacional. Disponível em: <https://www2.camara.leg.br/legin/fed/lei/1960-1969/lei-402420-dezembro-1961-353722-publicacaooriginal-1-pl.html>. Acesso em 28 dez 2020.

BRASIL. Lei no 5.692, de 11 de agosto de 1971. Fixa Diretrizes e Bases para o ensino de $1^{\circ} \mathrm{e}$ 20 graus, e dá outras providências. Disponível em: <https://www2.camara.leg.br/legin/fed/lei/1970-1979/lei-5692-11-agosto-1971-357752publicacaooriginal-1-pl.html>. Acesso em 17 dez 2020.

BRASIL. Decreto no 72.425, de 3 de julho de 1973. Cria o Centro Nacional de Educação Especial (CENESP), e dá outras providências. Disponível em: <https://www2.camara.leg.br/legin/fed/decret/1970-1979/decreto-72425-3-julho-1973420888-publicacaooriginal-1-pe.html>. Acesso em 27 dez 2020.

BRASIL. Leo no 9.394, de 20 de dezembro de 1996. Estabelece as diretrizes e bases da educação nacional. Disponível em: <http://www.planalto.gov.br/ccivil_03/leis/l9394.htm>. Acesso em 14 dez 2020.

BRASIL. Lei 10.436 de 24 de abril de 2002. Dispõe sobre a Língua Brasileira de Sinais - Libras e dá outras providências. Disponível em: <http://www.planalto.gov.br/ccivil_03/LEIS/2002/L10436.htm>. Acesso em 03 jan. 2020.

BRASIL. Lei no 14.191, de 3 DE agosto de 2021. Altera a Lei no 9.394, de 20 de dezembro de 1996 (Lei de Diretrizes e Bases da Educação Nacional), para dispor sobre a modalidade de educação bilíngue de surdos. Disponível em: <https://www.in.gov.br/en/web/dou/-/lei-n14.191-de-3-de-agosto-de-2021-336083749>. Acesso em 20 nov. 2021.

BRASIL. Saberes e práticas da inclusão: desenvolvendo competências para o atendimento às necessidades educacionais especiais de alunos surdos. 2 ed. SEESP/MEC. - Brasília: MEC, Secretaria de Educação Especial, 2006.

FERNANDES, Sueli. Práticas de letramento em contextos de educação bilingue para surdos. Revista Forum, n. 25-26, pp. 37-44. Disponível em $<$ https://www.ines.gov.br/seer/index.php/forum-bilingue/article/view/289/310>. Acesso em 08 dez 2021.

GEERTZ, Clifford. A interpretação das culturas. Rio de Janeiro: Zahar Editores, 1978.

HEIJI, Hugo. Comunidades surdas. Disponível em: <https://culturasurda.net/comunidadessurdas/>. Acesso em 05 jan. 2021. 
HORT, Ana Paula Fisher; HORT, Ivan Carlos. Educação Especial e Inclusão Escolar. Indaial: Uniassselvi, 2009.

KASSAR, Monica de Carvalho Magalhães. Educação especial na perspectiva da educação inclusiva: desafios da implantação de uma política nacional. Educar em Revista, Paraná, $\mathrm{n}$. 41, p.61-79, jul. 2011.

ORGANIZAÇÃO DAS NAÇÕES UNIDAS. Declaração Universal dos Direitos Humanos, 1948. Disponível em: <https://www.unicef.org/brazil/declaracao-universal-dos-direitos-humanos>. Acesso em 05 jan. 2021.

ORGANIZAÇÃO DOS ESTADOS AMERICANOS. Convenção Interamericana para a Eliminação de Todas as Formas de Discriminação contra a Pessoa Portadora de Deficiência, 1999. Disponível em: <https://www2.camara.leg.br/legin/fed/decleg/2001/decretolegislativo-19813-junho-2001-337086-convencao-1-pl.html>. Acesso em 05 jan. 2021.

PIETZAK, Julianne de Deus Corrêa; PROBST, Melissa. Bilinguismo e inclusão escolar dos alunos surdos. Revista Maiêutica, Indaial, v. 5, n. 01, p. 117-128, 2017.

QUADROS, Ronice Müller de. A educação de surdos na perspectiva da educação inclusiva no Brasil. Informativo Técnico-Científico Espaço, INES - Rio de Janeiro, n. 30, p.16, jul-dez 2008. Disponível em: <http://seer.ines.gov.br/index.php/revista-espaco/article/view/1110/1137>. Acesso em 06 jan. 2021.

QUADROS, Ronice Müller de. O Tradutor e Intérprete de Língua Brasileira de Sinais e Língua Portuguesa. Brasília: MEC/SEESP, 2004. Disponível em: <http://portal.mec.gov.br/seesp/arquivos/pdf/tradutorlibras.pdf>. Acesso em 22 dez 2020.

QUADROS, Ronice Müller de. Situando as diferenças implicadas na educação de surdos: inclusão/exclusão. Ponto de Vista, Florianópolis, n.05, p. 81-111, 2003. Disponível em: $<$ https://periodicos.ufsc.br/index.php/pontodevista/article/view/1246/3850>. Acesso em 05 jan. 2021.

SKLIAR, Carlos. La educación de los sordos. 2003a. Disponível em: http://modalidadespecial.educ.ar/datos/recursos/pdf/skliar-educacion-sordos-2003.pdf. Acesso em 10 dez. 2021.

SKLIAR, Carlos. A invenção e a exclusão da alteridade "deficiente" a partir dos significados da normalidade. Educação \& Realidade, n. 24, vol. 1 p. 15-32, 2003b.

SKLIAR, Carlos; QUADROS, Ronice. Invertendo epistemologicamente o problema da inclusão: os ouvintes no mundo dos surdos. Estilos clínicos, São Paulo, v. 5, n. 9, p. 32-51, 2000. Disponível em <http://pepsic.bvsalud.org/scielo.php?script=sci_arttext\&pid=S1415$71282000000200003 \&$ lng=pt\&nrm=iso>. acessos em 20 out. 2021.

SOUZA, Regina Maria; de Oliveira Lippe, Eliza Marcia Decreto 6.949/2009: avanço ou retorno em relação à Educação dos Surdos? Calidoscópio, vol. 10, núm. 1, jan-abr, 2012, pp. 12-23. 
SOUZA, Rita de Cácia Santos et al. Introdução aos estudos sobre Educação dos Surdos. Aracaju: Editora Criação, 2014.

UNESCO. Declaração de Salamanca. Sobre Princípios, Políticas e Práticas na Área das Necessidades Educativas Especiais, 1994. Disponível em: <http://portal.mec.gov.br/seesp/arquivos/pdf/salamanca.pdf> Acesso em 27 dez 2020.

WOODWARD, Kathryn. Identidade e diferença: uma introdução conceitual. In.: SILVA, Tomaz Tadeu da (org.). Identidade e diferença: a perspectiva dos estudos culturais. 11 ed. Petrópolis: Vozes, 2012.

Recebido em 28 de março de 2021.

Aprovado em 5 de dezembro de 2021.

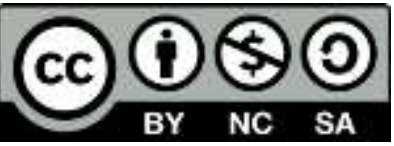

